\title{
Integration of rural and urban healthcare insurance schemes in China: an empirical research
}

\author{
Xin Wang ${ }^{1 *}$, Ang Zheng ${ }^{2}$, Xin $\mathrm{He}^{3}$ and Hanghang Jiang ${ }^{4}$
}

\begin{abstract}
Background: Despite the broad coverage of the healthcare insurance system in China, the imbalances in fairness, accessibility and affordability of healthcare services have hindered the universal healthcare progress. To provide better financial protection for the Chinese population, China's new medical reform was proposed to link up urban employee basic medical insurance scheme (UEBMI), urban resident basic medical insurance scheme (URBMI), new rural cooperative medical system (NRCMS) and urban and rural medical assistance programs. In this paper, we focused on people's expected healthcare insurance model and their willingness towards healthcare insurance integration, and we made a couple of relative policy suggestions.
\end{abstract}

Methods: A questionnaire survey was conducted in four cities in China. A total of 1178 effective questionnaires were retrieved. Statistical analysis was conducted with SPSS and Excel. Chi-square test and logistic regression model were applied.

Results and discussion: The payment intention and reimbursement expectation of the three groups varied with NRCMS participants the lowest and UEBMI participants the highest. In economic developed areas, rural residents had equal or even stronger payment ability than urban residents, and the overall payment intention showed a scattered trend; while in less developed areas, urban residents had a stronger payment ability than rural residents and a more concentrated payment intention was observed. The majority of participants favored the integration, with NRCMS enrollees up to $80.5 \%$. In the logistic regression model, we found that participants from less developed areas were more likely to oppose the integration, which we conceived was mainly due to their dissatisfaction with their local healthcare insurance schemes. Also the participants with better education background tended to oppose the integration, which might be due to their fear of benefit impairment and their concern about the challenges ahead.

Conclusion: Even though there are many challenges for healthcare insurance integration, it has received strong support from the mass population. However, more emphasis shall be put on equal financing and equal benefit when making further policies. As the current healthcare policies share the same design concept, principle and method, the ultimate goal of establishing a universal healthcare system is promising.

Keywords: Urban and rural healthcare insurance, Coordinated development, Empirical research

\section{Background}

China's new medical reform established the goal of establishing the basic healthcare system and that everyone would have access to basic healthcare services covering both urban and rural residents. Generally speaking, the current healthcare insurance system in China falls into three categories, namely, the urban employee basic medical

\footnotetext{
* Correspondence: wxinsmile@qq.com

'Department of the Health Service Management, China Medical University, No.92 North Second Road, Heping District, Shenyang, Liaoning Province 110001, China(PRC)

Full list of author information is available at the end of the article
}

insurance scheme (UEBMI), urban resident basic medical insurance scheme (URBMI), and new rural cooperative medical system (NRCMS). In general, UEBMI stipulates that the employment-based basic health insurance scheme should cover urban employees, including employees from both public and private enterprises. Self-employed and rural industry workers are not included in UEBMI, and need to buy into the program. Retired workers are exempted from premium contributions, and their former employers should shoulder the costs of their contribution [1]. It forms riskpooling units, which are created independently for each city

\section{Biomed Central}


or county or district [2]. URBMI, started in July 2007, was aimed to cover 240 million urban residents outside the workforce, and all urban residents would become beneficiaries by 2010 [3]. Its chief enrollees include children, college students, and migrant workers [1]. In addition to individual premiums, it is financed by central and local governments, and the funding amount per capita is approximately RMB 150 to RMB 500 (\$1 US =6.5 RMB) [2]. NRCMS is a greatly subsidized voluntary health insurance program for rural residents. It serves as a replacement for the old village-based rural health insurance program, which operates at the county level to provide a larger risk pool and economies of scale in organization and management [4]. NRCMS, started in 2003 and covering rural residents, is jointly funded by central and local governments and premium. A majority of URBMI and NRCMS benefit packages cover only inpatient care, while an increasing number of Chinese cities and counties have expanded their benefit packages to include outpatient care [5]. By the end of 2011, 97.5\% of the Chinese population has been covered by the above-mentioned healthcare insurance schemes. Significant increases in the availability of healthcare insurances have been witnessed. Furthermore, a sheer reduction in the inequality of healthcare insurance between the poorest and wealthiest economic groups and regions has been observed $[6,7]$. Figure 1 presented the changing tendency of different population groups covered by healthcare insurance from the year 2003 to 2011 .

The current healthcare insurance schemes in China have contributed to an overall improvement in its accessibility in the general population. In addition, the schemes increased outpatient and inpatient utilization and reduced

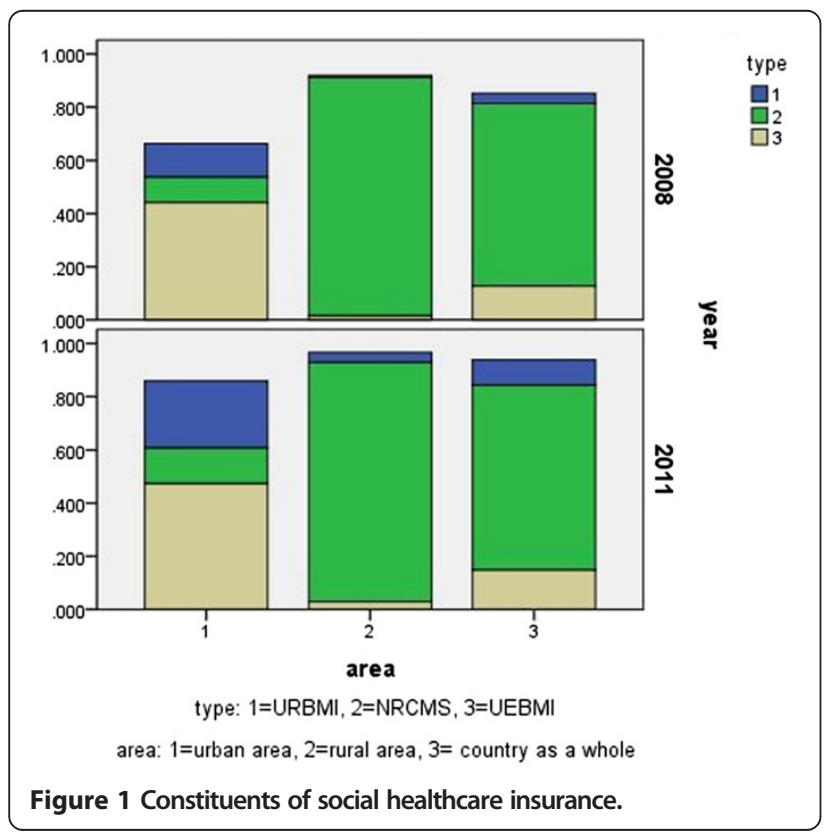

delivery costs [7]. However, the imbalances in fairness, accessibility and affordability of the medical services have hindered the universal healthcare progress. The out-ofpocket payment for healthcare services remained to be high, and the financial burdens placed on individual households continued to increase, especially in the rural population, for whom the out-of-pocket payment as a share of average annual household living consumption expenditure continued to increase from $5.2 \%$ in 2000 to $8.4 \%$ in 2011 [8]. To provide a better financial protection for the vulnerable Chinese seeking essential healthcare, China's new medical reform was proposed to link up UEBMI, URBMI, NRCMS and urban and rural medical assistance programs. Besides, the integration would also cope with the rapid urbanization that more rural residents transit to cities for employment, as the current static and separate operation mechanisms with poor interconnections would fail to meet the dynamic healthcare needs of different population groups [9].

The integrated universal healthcare insurance, though promising, faces a variety of challenges in aspects like cohesion of financing, management, payment, and service. The multiple admission standards in the current insurance system, such as census register standard (agricultural registered permanent residence and non-agricultural registered permanent residence), employment standard (practitioners with residents), and industry department standard (public officials and ordinary workers), need to be balanced to meet the healthcare needs of different population groups. In this case, mass support is a prerequisite for the successful implementation of integration. In this paper, we specifically studied people's willingness towards the integration of healthcare systems and analyzed the factors associated with it.

\section{Methods}

\section{Study sample}

We conducted a household survey in four purposively selected cities, namely, Foshan, Changshu, Shenyang and Changchun. Foshan is the third biggest city in Guangdong province, with over \$11,000 GDP per capita; Changshu, though a county-level city, is an economically developed city in Jiangsu province with over \$20,000 GDP per capita; Shenyang is the capital city of Liaoning province, with around \$ 10,000 GDP per capita; Changchun is the capital city of Jilin province, with around \$ 9,000 GDP per capita (Table 1). Due to the different economic levels of the cities, some hints might be got on the status quo of healthcare insurance in different economic backgrounds. Furthermore, the healthcare insurance schemes also vary in different cities (Table 2). And the healthcare insurance administration also differs from city to city: unification of healthcare insurance administration has been achieved in Foshan, Changshu and Shenyang; while in Changchun, several 
Table 1 Basic information of the four cities

\begin{tabular}{lllll}
\hline Indicators & Foshan & Changshu & Shenyang & Changchun \\
\hline Total population $(\mathrm{N} \times 104)$ & 726.2 & 150.7 & 822.8 & 758.9 \\
Per capita GDP (RMB) & 86073 & 123882 & 80532 & 52649 \\
UEBMl enrollment (N) & 242.4 & 38.9 & 351.2 & 151.0 \\
URBMI enrollment (N) & 205.8 & 12.2 & 110.8 & 239.2 \\
NRCMS enrollment (N) & 205.0 & 43.2 & 228.3 & 377.0 \\
\hline
\end{tabular}

departments take charge of the insurance scheme. By conducting the survey with participants with four different healthcare insurance schemes, we could better understand the most suitable model, which could be taken as a reference for the future policy making. The survey was undertaken in both urban and rural areas of the four cities, and was conducted with trained interviewers in each city to collect data from different population groups, namely, urban employees, urban residents and rural residents.

To interview the target population, a questionnaire was developed with three sections. Section A was designed to collect demographic information, including age, gender, education background, household economic status, recent health status, current health status, insurance enrollment status, etc. Section B was designed to study people's payment intention and reimbursement expectation. Section $\mathrm{C}$ was designed to collect information about people's willingness towards the integration of UEBMI, URBMI and NRCMS and the corresponding reasons. Informed consent was obtained from all participants following the protocol approved by Ethics Committee of China Medical University.

A total of 1200 questionnaires were distributed, with 300 in each city and 100 in every population group. We retrieved a total of 1187 questionnaires, among which 1178 were effective. The effective response rate is $98.17 \%$.

\section{Measures}

\section{Demographic characteristics}

The demographic information collected for the current study included each participant's gender, age, type of insurance, education background and household income. The respondents were classified in accordance with their insurance type: URBMI enrollees, NRCMS enrollees and UEBMI enrollees. The annually household income was measured in Chinese Yuan as a continuous variable.

\section{Payment intention}

In order to measure people's will to pay for the healthcare insurance, nine reasonable payment ranges were offered in the questionnaire, which we defined in this paper: $1=$ "20 yuan or below", $2=$ "21-50 yuan", $3=$ " $51-100$ yuan", $4=$ "101-200 yuan", $5=$ " $201-300$ yuan", 6 = "301-500 yuan", 7 = "501-800 yuan", 8 = "8011000 yuan", and $9=$ "above 1000 yuan".

\section{Reimbursement expectation}

To understand a reasonable reimbursement ratio, the survey was conducted with eight options, which we defined in this paper: $1=$ "below $30 \%$ ", $2=$ " $31 \%-40 \%$ ", $3=$ " $41 \%-$ $50 \% ", \quad 4=$ " $51 \%-60 \% ", \quad 5=$ " $61 \%-70 \% ", \quad 6=$ "71\%-80\%", $7=$ " $81 \%-90 \% "$, and $8=$ "above $91 \% "$.

\section{Preferred healthcare insurance package}

For better understanding of the respondents' expected healthcare insurance model, three benefit packages were proposed. Package 1: pay 20 yuan every year and the reimbursement ratio is $30 \%$ to $40 \%$; Package 2: pay 120 yuan every year and the reimbursement ratio is $50 \%-60 \%$; Package 3: pay 500 yuan every year and the reimbursement ratio is $70 \%-80 \%$.

\section{Data analysis}

SPSS 17.0 and Excel were used for data analysis. Demographic characteristics of URBMI enrollees, NRCMS enrollees and UEBMI enrollees, including age, gender, education level and current health status were described (Table 3). Chi-square test was used to examine the differences between groups based on the above characteristics.

As there were three options for the integration willingness towards the three insurance schemes in the questionnaire, namely, "support", "oppose", "not sure", multinomial logistic regression was applied to examine the relationship between insurance type, age, gender, education, current health status, average family annual income and integration willingness. The dependent variable was the integration willingness, where 1 = "supporting", 2 = "opposing" and $3=$ "not sure". Independent variables included insurance type $(1=$ URBMI, $2=$ NRCMS, $3=$ UEBMI), age $(1=$ 20 or younger, $2=41$ or older, $3=20-40)$, gender $(1=$ male, $2=$ female), education $(1=$ elementary or lower, $2=$ college or higher, $3=$ secondary to high school), current health status $(1=$ healthy, $2=$ ill), average family annual income $(1=$ 10000 or 10000 below, $2=20000$ above, $3=10000-20000$ ) and integration willingness. Statistical significance was defined as $\mathrm{P} \leq 0.05$.

Furthermore, payment intention, reimbursement expectation, preferred healthcare scheme, integration willingness and the corresponding reasons were described.

\section{Results}

\section{Characteristics of study sample}

The sample generated for analysis in our study included a total of 1178 individuals. Table 3 presented the demographic characteristics of the respondents grouped by their insurance type. The age distribution of the three groups differed significantly $\left(X^{2}=72.150, d f=4, P<0.001\right)$. UECMS group mainly consisted of the population of 20-40 years old, while the majority of URBMI and NRCMS were of over 40 years old. Education level among the three groups 
Table 2 Comparison of the health insurance schemes in the four cities

\begin{tabular}{|c|c|c|c|c|c|}
\hline & & Changshu & Foshan & Shenyang & Changchun \\
\hline \multirow[t]{2}{*}{ NRCMS } & $\begin{array}{l}\text { The minimum } \\
\text { deduction line and } \\
\text { the correspongding } \\
\text { deduction rate }\end{array}$ & 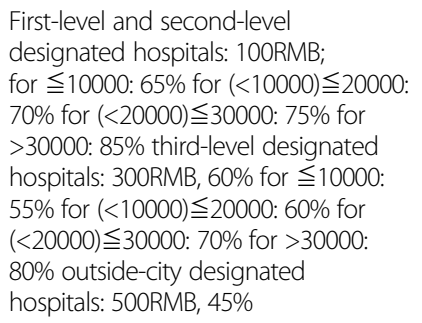 & $\begin{array}{l}\text { First-level designated hospitals: } 300 \text { RMB } \\
\text { second-level designated hospitals: } 500 \text { RMB } \\
\text { third-level designated hospitals: } 700 \text { RMB for } \\
\text { male } \geq 60 \text { years old or female } \geq 55 \text { years old, } \\
\text { the reimbursment rate is } 95 \% \text {; for the rest, } \\
\text { the reimbursement rate is } 90 \%\end{array}$ & $\begin{array}{l}\text { First-level designated hospitals: } 50 \text { RMB, } \\
80 \% \text { second-level designated hospitals: } \\
200 \text { RMB, 65\% third-level designated } \\
\text { hospitals: 600RMB, } 40 \%\end{array}$ & $\begin{array}{l}\text { First-level designated hospitals: } 300 \text { RMB, } \\
70 \% \text { second-level designated hospitals: } \\
400 \text { RMB, } 60 \% \text { third-level designated } \\
\text { hospitals: } 500 \text { RMB, 45\% }\end{array}$ \\
\hline & $\begin{array}{l}\text { The maximum } \\
\text { deduction line }\end{array}$ & 100000 RMB & $30000 \mathrm{RMB}$ & 30000RMB & $30000 \mathrm{RMB}$ \\
\hline \multirow[t]{2}{*}{ URBMI } & $\begin{array}{l}\text { The minimum } \\
\text { deduction line and } \\
\text { the correspongding } \\
\text { deduction rate }\end{array}$ & $\begin{array}{l}\text { As Changshu has integrated } \\
\text { NRCMS with URCMS, they } \\
\text { share the same standards }\end{array}$ & $\begin{array}{l}\text { First-level designated hospitals: } 400 \text { RMB, } \\
85 \% \text { second-level designated hospitals: } \\
600 \text { RMB, } 75 \% \text { third-level designated } \\
\text { hospitals: } 1200 \text { RMB, } 50 \%\end{array}$ & $\begin{array}{l}\text { First-level designated hospitals: for } \\
\text { adults and aged residents:200RMB, } \\
\text { 90\% for students and juveniles: } 100 \text { RMB, } \\
90 \% \text { second-level designated hospitals: } \\
\text { for adults and aged residents:400 RMB, } \\
\text { 80\% for students and juveniles: } 200 \text { RMB, } \\
\text { 85\% third-level designated hospitals: for } \\
\text { adults and aged residents:600 RMB, 75\% } \\
\text { for students and juveniles: } 300 \text { RMB, 78\% }\end{array}$ & 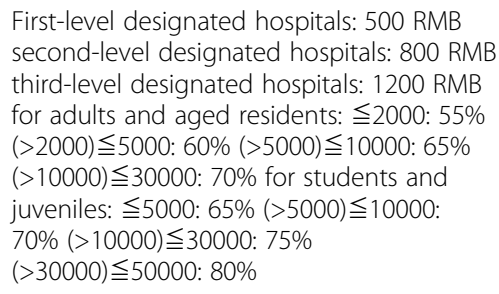 \\
\hline & $\begin{array}{l}\text { The maximum } \\
\text { deduction line }\end{array}$ & & 160000 RMB & $\begin{array}{l}\text { For adults and aged residents:80000 RMB; } \\
\text { for students and juveniles: } 125000 \text { RMB }\end{array}$ & $\begin{array}{l}\text { For adults and aged residents:30000 RMB; } \\
\text { for students and juveniles: 50000RMB }\end{array}$ \\
\hline \multirow[t]{2}{*}{ UEBMI } & $\begin{array}{l}\text { The minimum } \\
\text { deduction line and } \\
\text { the correspongding } \\
\text { self-payment ratio }\end{array}$ & $\begin{array}{l}\text { For in-service employees: first-level } \\
\text { designated hospitals: } 400 \text { RMB } \\
\text { second-level designated hospitals: } \\
600 \text { RMB third-level designated } \\
\text { hospitals: } 1000 \text { RMB for retired em } \\
\text { ployees: the minimum deduction } \\
\text { line is half of the corresponding } \\
\text { in-service employees minimum } \\
\text { deduction line } \leqq 10000: 12.8 \% \\
(>10000) \leqq 30000: 9.6 \% \\
(<30000) \leqq 50000: 6.4 \%\end{array}$ & $\begin{array}{l}\text { For in-service employees: first-level } \\
\text { designated hospitals: } 400 \mathrm{RMB} \text {; } 2 \% \\
\text { second-level designated hospitals: } \\
\text { 600RMB; 10\% third-level designated } \\
\text { hospitals: 1200RMB; } 15 \% \text { for retired } \\
\text { employees: irst-level designated } \\
\text { hospitals: 300RMB; 0\% second-level } \\
\text { designated hospitals: 500RMB; } 7 \% \\
\text { third-level designated hospitals: } \\
\text { 1000RMB; 15\% }\end{array}$ & $\begin{array}{l}\text { For in-service employees: first-level } \\
\text { designated hospitals: } 300 \text { RMB; } 6 \% \\
\text { second-level designated hospitals: } \\
500 \text { RMB; } 7 \% \text { third-level designated } \\
\text { hospitals: } 800 \text { RMB; } 12 \% \text { for retired } \\
\text { employees: irst-level designated } \\
\text { hospitals: } 300 \text { RMB; } 3 \% \text { second-level } \\
\text { designated hospitals: } 500 \text { RMB; } 4 \% \\
\text { third-level designated hospitals: } \\
800 \text { RMB; } 9 \%\end{array}$ & $\begin{array}{l}\text { The minimum deduction line is based on } \\
\text { the average salary of Changchun last year } \\
\text { first-level designated hospitals:9\% second-level } \\
\text { designated hospitals: 500RMB; } 12 \% \text { third-level } \\
\text { designated hospitals: 800RMB; } 15 \%\end{array}$ \\
\hline & $\begin{array}{l}\text { The maximum } \\
\text { deduction line }\end{array}$ & $50000 \mathrm{RMB}$ & $\begin{array}{l}200000 \text { RMB (including } \\
\text { supplemented insurance) }\end{array}$ & $100000 \mathrm{RMB}$ & $\begin{array}{l}4 \text { times of the average salary of } \\
\text { Changchun last year }\end{array}$ \\
\hline
\end{tabular}

Note: the standards above mainly refer to the in-patient care for the first time. 
Table 3 Demographic characteristics of enrollees of URCMS, NRCMS and UECMS

\begin{tabular}{|c|c|c|c|c|}
\hline & & URBMI & NRCMS & UEBMI \\
\hline Amount (N) & & 392 & 391 & 395 \\
\hline \multirow[t]{3}{*}{ Gender (\%) } & Male & 54.8 & 47.5 & 56.7 \\
\hline & Female & 46.2 & 52.5 & 43.3 \\
\hline & & & & $X^{2}=7.345, d f=2, P=0.025$ \\
\hline \multirow[t]{4}{*}{ Age (\%) } & 20 or younger & 11.0 & 3.1 & 0 \\
\hline & $21-40$ & 40.4 & 36.8 & 51.8 \\
\hline & 41 or older & 48.4 & 60.1 & 48.2 \\
\hline & & & & $X^{2}=72.150, d f=4, P<0.001$ \\
\hline \multirow[t]{4}{*}{ Education level (\%) } & Elementary or lower & 33.3 & 62.5 & 13.6 \\
\hline & Secondary to high school & 35.9 & 24.7 & 26.2 \\
\hline & College or higher & 30.8 & 12.8 & 60.2 \\
\hline & & & & $X^{2}=272.922, d f=4, P<0.001$ \\
\hline \multirow[t]{3}{*}{ Health status (\%) } & Healthy & 80.1 & 79.5 & 84.0 \\
\hline & III & 19.9 & 20.5 & 16.0 \\
\hline & & & & $X^{2}=3.015, d f=2, P=0.221$ \\
\hline
\end{tabular}

also differed significantly $\left(\mathrm{X}^{2}=272.922, \mathrm{df}=4, \mathrm{P}<0.001\right)$. Compared with NRCMS and URBMI enrollees (12.8\% and $30.8 \%$ ), more UEBMI enrollees have received college or higher education (60.2\%).

\section{Payment intention}

Table 4 showed that $25.1 \%$ of the NRCMS enrollees considered "21-50 yuan" to be the reasonable payment range, followed by $19.4 \%$ choosing " $51-100$ yuan" and 14.1\% choosing "101-200 yuan", presenting an overall concentrated pattern. Meanwhile, for the URBMI enrollees, "101-200 yuan" was considered the reasonable payment range by $28.6 \%$ of the respondents, followed by "51-100 yuan" (24.8\%) and "21-50 yuan" (14.3\%). For the UEBMI enrollees, the payment intention presented a dispersed pattern: $15.9 \%$ of "101-200 yuan", $15.2 \%$ of "501-800 yuan", 14.9\% of "301-500 yuan", and $14.4 \%$ of "above 1000 yuan".

When analyzed by regions, in economic developed areas like Foshan and Changshu, rural residents had equal or even stronger payment ability than urban residents, and the overall payment intention presented a scattered trend, as was shown in Figure 2. While in less economically developed areas like Changchun and Shenyang, urban residents had a stronger payment ability than rural residents and more concentrated payment intention could be observed.

\section{Reimbursement expectation}

Among the three groups of population, NRCMS enrollees presented the lowest reimbursement expectation: $27.4 \%$ chose "71\%-80\%", 25.6\% chose "81\%-90\%", 10.7\% chose "51\%-60\%". A more concentrated pattern could be observed in URBMI enrollees: $31.4 \%$ chose "71\%$80 \%$ ", 30.1\% chose "81\%-90\%", 19.6\% chose "above 90\%". And UEBMI enrollees held the highest reimbursement expectation: $38.2 \%$ chose " $81 \%-90 \%$ ", $37.5 \%$ chose "above 90\%", 18.7\% chose "71\%-80\%".

As was shown in Figure 3, urban employees, urban residents and rural residents in Foshan, compared with these in the other three cities, had the highest and similar reimbursement expectations. In addition, in Changshu, urban employees had higher reimbursement expectations, while urban and rural residents shared similar and lower expectations, which is consistent with the local policy of integrating rural resident healthcare insurance with urban resident healthcare insurance. In Shenyang, reimbursement expectations of the three groups were mainly distributed at three intervals. In Changchun, generally low and scattered reimbursement expectations have been witnessed: rural residents held the lowest reimbursement expectations and urban employees held the highest reimbursement expectations.

\section{Preferred healthcare insurance package}

Given the three benefit packages, with the best healthcare treatment in Package 3, followed by Package 2 and Package 1, a majority of URBMI (57.9\%) and NRCMS (47.1\%) enrollees preferred Package 2, and $36.7 \%$ of UECMS enrollees chose it. While the majority of UECMS enrollees took a fancy to Package 3, taking up 57.7\%.

In Figure 4, the majority of Foshan and Changshu participants preferred Package 3, while the majority of Shenyang and Changchun participants preferred Package 2. Furthermore, in the same area, people's preference differed within the same group, regardless of the economic level. 
Table 4 Payment intention, reimbursement expectation, prefferred healthcare insurance model, integration willingness and reasons of URCMS, NRCMS and UECMS enrollees

\begin{tabular}{|c|c|c|c|c|}
\hline & & URBMI (\%) & NRCMS (\%) & UEBMI (\%) \\
\hline \multirow[t]{10}{*}{ Payment intention } & 20 yuan or below & 4.8 & 10.2 & 4.8 \\
\hline & $21-50$ yuan & 14.3 & 25.1 & 8.4 \\
\hline & 51-100 yuan & 24.8 & 19.4 & 9.9 \\
\hline & $101-200$ yuan & 28.6 & 14.1 & 15.9 \\
\hline & 201-300 yuan & 10.7 & 9.5 & 7.4 \\
\hline & 301-500 yuan & 9.4 & 5.1 & 14.9 \\
\hline & $501-800$ yuan & 3.6 & 4.3 & 15.2 \\
\hline & $801-1000$ yuan & 1.8 & 7.4 & 9.1 \\
\hline & above 1000 yuan & 2.0 & 4.9 & 14.4 \\
\hline & Total & 100.0 & 100.0 & 100.0 \\
\hline \multirow[t]{9}{*}{ Reimbursement expectation } & $30 \%$ or below & 0.0 & 3.6 & 0.0 \\
\hline & $31 \%-40 \%$ & 3.6 & 4.6 & 0.0 \\
\hline & $41 \%-50 \%$ & 4.1 & 5.6 & 1.5 \\
\hline & $51 \%-60 \%$ & 5.1 & 10.7 & 1.8 \\
\hline & $61 \%-70 \%$ & 6.1 & 5.1 & 2.3 \\
\hline & $71 \%-80 \%$ & 31.4 & 27.4 & 18.7 \\
\hline & $81 \%-90 \%$ & 30.1 & 25.6 & 38.2 \\
\hline & above $90 \%$ & 19.6 & 17.4 & 37.5 \\
\hline & Total & 100.0 & 100.0 & 100.0 \\
\hline \multirow{4}{*}{$\begin{array}{l}\text { Preferred healthcare } \\
\text { insurance package }\end{array}$} & Package 1 & 11.7 & 19.2 & 5.6 \\
\hline & Package 2 & 57.9 & 47.1 & 36.7 \\
\hline & Package 3 & 30.4 & 33.7 & 57.7 \\
\hline & Total & 100.0 & 100.0 & 100.0 \\
\hline \multirow[t]{4}{*}{ Integration willingness } & Support & 69.6 & 80.5 & 57.7 \\
\hline & Oppose & 18.9 & 8.2 & 30.6 \\
\hline & Not sure & 11.5 & 11.3 & 11.7 \\
\hline & Total & 100.0 & 100.0 & 100.0 \\
\hline \multirow{8}{*}{$\begin{array}{l}\text { Reasons of supporting healthcare } \\
\text { insurance integration }\end{array}$} & It would achieve equal access to healthcare services. & 45.0 & 65.7 & 64.0 \\
\hline & There would be more options of hospital for participants. & 48.7 & 40.6 & 27.1 \\
\hline & It would reduce the healthcare gap between urban and rural areas. & 31.5 & 38.4 & 38.5 \\
\hline & Participants would enjoy better healthcare services. & 35.8 & 27.3 & 47.9 \\
\hline & It would improve the overall risk resistance ability of insuran scheme. & 12.4 & 10.1 & 25.8 \\
\hline & It would facilitate the labour flow between urban and rural areas. & 6.2 & 8.8 & 17.1 \\
\hline & It would reduce the administration costs. & 7.6 & 3.4 & 14.4 \\
\hline & Others. & 1.8 & 2.2 & 1.7 \\
\hline \multirow{7}{*}{$\begin{array}{l}\text { Reasons of opposing healthcare } \\
\text { insurance integration }\end{array}$} & The payment and treatment standards of the systems are different. & 36.4 & 46.8 & 31.4 \\
\hline & Administration of insurance may fall behind after integration. & 39.1 & 28.1 & 32.2 \\
\hline & Urban and rural participants have different healthcare needs. & 31.0 & 46.8 & 21.4 \\
\hline & $\begin{array}{l}\text { Some pilot areas should be implemented before implementation on a } \\
\text { large scale. }\end{array}$ & 28.3 & 21.8 & 25.6 \\
\hline & Some people may take advantage of the integrated insurance scheme & 33.7 & 34.3 & 17.3 \\
\hline & The conditions for integration are not yet ripe. & 29.7 & 25.0 & 13.0 \\
\hline & Others. & 25.6 & 40.6 & 18.1 \\
\hline
\end{tabular}




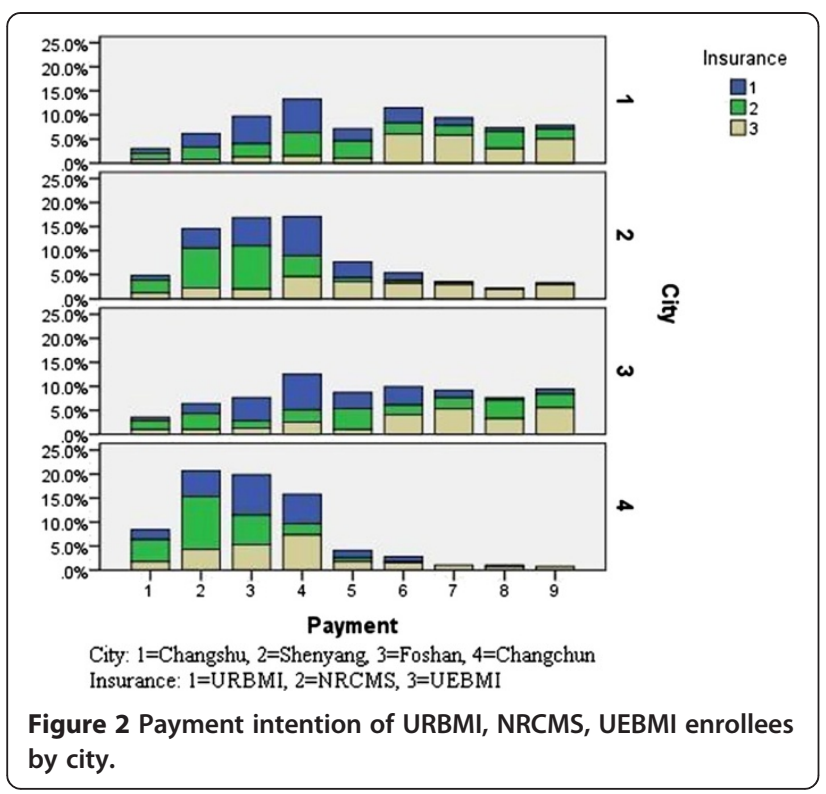

Integration willingness and the corresponding reasons

Among the 1178 respondents, 816 individuals were in support of the integration of NRCMS, URBMI and UEBMI, accounting for $69.3 \%$. The majority of URCMS, NRCMS and UEBMI enrollees were in favor of the integration, taking up $69.6 \%, 80.5 \%$ and $57.7 \%$, respectively. However, $30.6 \%$ of the UEBMI enrollees, $8.2 \%$ of the NRCMS enrollees and $18.9 \%$ of the URBMI enrollees opposed the integration.

The top reason for the integration was that it would achieve equal access to healthcare services for both rural and urban participants. Also a great number of supporters believed that they would have more choices of hospitals after integration. Other main reasons were that it would narrow the healthcare gap between urban and rural areas, and that the participants would enjoy better healthcare services.

The most common reason against the integration was that the payment ranges and benefit packages in the current insurance schemes were quite different, making it hard and unsuitable to integrate. Some participants also worried that the administration might fall behind after integration and the healthcare needs of urban and rural participants were different, as details described in Table 4.

\section{Factors associated with integration willingness}

In the multinomial logistic regression model (Table 5), a participant was more likely to oppose the integration in less economically developed areas, which, in this case, was Changchun. It indicated that the economic background of the coordinated area might affect people's willingness towards integration. Furthermore, participants' education background might also play a role in the integration willingness. In our study, surprisingly, we found people with higher education levels were more likely to oppose the integration.

\section{Discussion}

China's healthcare insurance system has multiple admission standards and multiple divisions, which go against the status quo of flow of personnel, and may jeopardize the robustness and sustainability of healthcare insurance financing through the allocating the risk to public, directly doing harm to the efficiency of operation [10]. Take the example of NRCMS, which is designed exclusively for

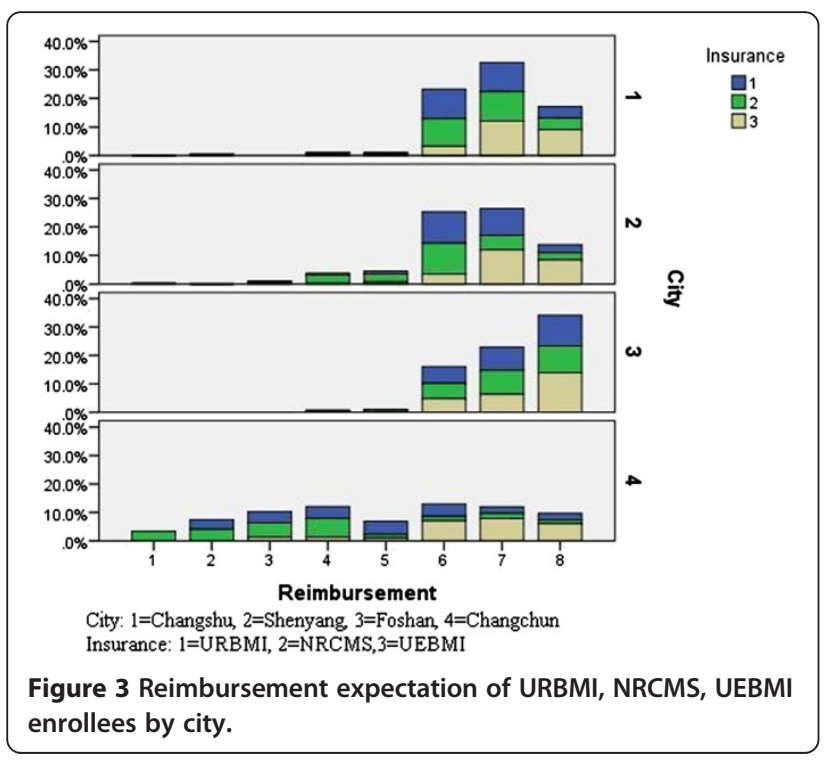

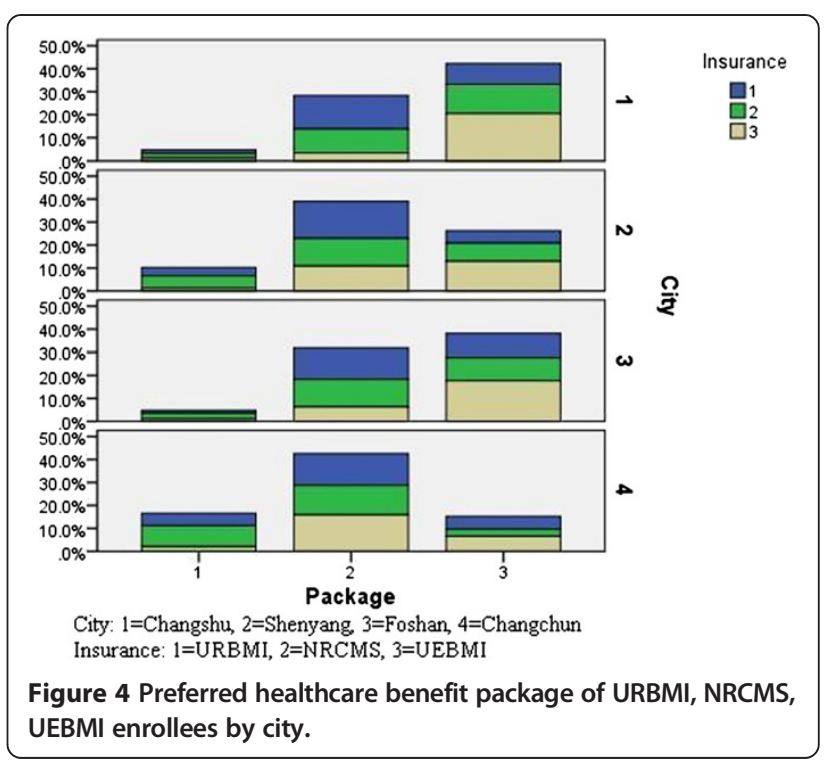


Table 5 Results of logistic regression on factors affecting integretion willingness

\begin{tabular}{|c|c|c|c|c|c|c|}
\hline & \multicolumn{3}{|c|}{ Support } & \multicolumn{3}{|c|}{ Oppose } \\
\hline & B & Odds ratio $(95 \% \mathrm{Cl})$ & $\mathbf{P}$ & B & Odds ratio $(95 \% \mathrm{Cl})$ & $\mathbf{P}$ \\
\hline Male & 0.039 & $1.040(0.722-1.497)$ & 0.834 & 0.266 & 1.305 (0.851-2.003) & 0.223 \\
\hline Age $<20$ & -0.391 & $0.676(0.283-1.618)$ & 0.380 & 0.333 & $1.394(0.553-3.515)$ & 0.481 \\
\hline Age $>40$ & 0.007 & 1.007 (0.691-1.467) & 0.972 & -0.348 & $0.706(0.454-1.100)$ & 0.124 \\
\hline URBMI & 0.202 & $1.224(0.783-1.914)$ & 0.376 & -0.470 & $0.625(0.378-1.033)$ & 0.067 \\
\hline NRCMS & 0.368 & $1.444(0.924-2.259)$ & 0.107 & -1.286 & $0.276(0.157-0.488)$ & $P<0.001$ \\
\hline Elementary school or lower & 0.083 & 1.087 (0.697-1.695) & 0.713 & -0.835 & $0.434(0.230-0.817)$ & 0.010 \\
\hline College or higher & -0.286 & $0.752(0.472-1.197)$ & 0.229 & 1.091 & $2.979(1.738-5.104)$ & $P<0.001$ \\
\hline Household annual income per capita $<10000$ RMB & 0.355 & $1.426(0.912-2.230)$ & 0.119 & -0.956 & $0.384(0.195-0.759)$ & 0.006 \\
\hline Household annual income per capita $\geqq 20000$ RMB & -0.257 & $0.774(0.497-1.205)$ & 0.256 & 1.017 & $2.764(1.694-4.509)$ & $P<0.001$ \\
\hline Foshan & -0.314 & $0.730(0.491-1.244)$ & 0.248 & -0.041 & $0.960(0.515-1.789)$ & 0.960 \\
\hline Shenyang & -0.097 & $0.907(0.526-1.564)$ & 0.726 & -0.185 & $0.831(0.434-1.590)$ & 0.831 \\
\hline Changchun & -0.573 & $0.564(0.335-0.948)$ & 0.031 & -0.031 & $0.970(0.531-1.770)$ & 0.970 \\
\hline
\end{tabular}

Integration willingness ( 1 = support, 2 = oppose, $3=$ not sure).

rural people according to their hukou [4], the enrollees are expected to seek medical services in the designated hospitals, most of which are located within the home county, which is impractical for the migrant job seekers far away from home, limiting their NRCMS benefits. Furthermore, the migrants are also facing the lack of accessibility to healthcare insurance in cities, as most of them are not qualified for UEBMI and URBMI $[11,12]$.

In 2009, a new round of healthcare system reform has been initiated, aiming to ensure that the State plays a critical role in guaranteeing universal coverage of essential healthcare and providing efficient, convenient and affordable basic healthcare services [13]. Four aspects of healthcare system covering both urban and rural residents are involved in the reform: health insurance schemes, national essential drug systems, clinical service systems and the public health/preventive service systems. Hitherto, the healthcare insurance schemes in China have achieved phasic success. Despite the increasing coverage of population, unfairness, inequality and unaffordability of the healthcare services have hindered the universal healthcare progress, which might also affect people's enthusiasm for participating in the healthcare insurances. It should be noted that their lack of participation will not only lead to adverse selection but also to considerably higher administrative costs [14].

\section{Healthcare insurance expectations, healthcare insurance integration willingness and associated factors}

To promote the participation in healthcare insurances and to smoothly integrate UEBMI, URBMI and NRCMS, the voices of mass population should be heard. Our data revealed that the expected payment range of urban employees presented a dispersed trend, while that of urban residents and rural residents presented a concentrated pattern (Figure 2). This could be explained by the fact that the insurance payment of urban employees is proportional to their salaries, while for urban and rural residents, the quota payment, which sets a payment standard for enrollees, limits their choices. The UEBMI guideline established by State Council suggests premium contributions by employers and employees be set at $6 \%$ and $2 \%$ of an employee's salary, respectively [15]. While according to a URBMI survey conducted by State Council, the average per capita financing level of the pilot cities in 2007 reached 236 RMB for adults and 97 RMB for minors. About 36\% and $50 \%$ of these amounts, respectively, were contributed by government subsidies, indicating that the majority of funding was obtained from individual contributions [7]. The total government subsidies for NRCMS enrollees were 80 RMB per rural resident in 2009, of which central and local government each contributed 40 RMB. Meanwhile, individual contributions rose to $20 \mathrm{RMB}$ per enrollee and the average financing level increased to $100 \mathrm{RMB}$ per enrollee in 2009 [16]. As the healthcare insurance systems of URBMI and NRCMS have been integrated in some areas, the participants shared the same reimbursement expectations (Figure 3). In addition, as indicated in our study, people in economically developed areas showed higher payment intention, higher reimbursement expectation as well as better insurance benefit package. In addition, according to the 2008 National Health Service Survey [17], income level was a major determinant of health outcomes. Therefore, the economic status of participants from different areas and different population groups should be taken as a reference when setting the payment standard and benefit package.

As noted in Table 4, rural residents were the most supportive of healthcare insurance integration, with the most common reason of achieving equal access to healthcare services. On the other hand, people who strongly opposed 
the integration mainly held that the gaps in the insurance coverage and healthcare benefits across different schemes remained to be so wide that it was unwise to integrate them at this moment. Despite the increasing coverage of healthcare insurance nationally [18], the access to healthcare services remained to be uneven, and the integration would not only promote the benefits for rural residents, but will also provide much convenience for rural migrants seeking medical care in cities. Jian and his colleagues have reported that even though rural Chinese with chronic disease could more easily start inpatient treatment in 2008 than they could in 2003, they were more than twice as likely to drop out of treatment as were Chinese in urban areas due to the higher hospital copayments required under insurance coverage for rural citizens [19]. Therefore, in the process of coordinating urban and rural healthcare insurance schemes, the economic background should not be neglected. The logistic regression model in Table 5 indicated that participants in Changchun were more likely to oppose the integration than the participants in the other three cities, reflecting that the enrollees in Changchun were not satisfied with the current insurance schemes. Also we found that people with better education background tended to oppose the integration, which might seem contradictory to the common sense. We proposed two reasons for it: on one hand, as no complete integration policy has been implemented yet, they might concern that the integration would drag down their healthcare benefits; on the other hand, they might be better aware of the underlying challenges of integration, involving limited financial risk pooling, inefficient purchasing and provider incentives, etc. In this case, a proper balance of benefits among each group is crucial in improving the healthcare scheme.

\section{Policy implication}

According to the feedback from the enrollees, we have come up with the following suggestions to improve the healthcare insurance policy.

Setting up a multi-grade payment and treatment standard: For developed areas, high subsidies are provided to ensure that urban and rural residents receive improved or even equivalent healthcare treatment as urban employees (such as Changshu and Foshan). While for most parts of China, where the income of urban and rural residents differ greatly and the local fund is limited, a proper fundraising mechanism with multiple standards is needed in the transitional stage, so that participants could choose the grade according to their own economic background.

Constructing an integrated healthcare insurance information system: For areas that are immature to integrate URBMI and NRCMS, instead of leaping to the integration, a unified information platform shall be established as the first move towards the integration.
Unifying the administration: To improve the poor interconnections due to the separate healthcare administrative institutions, a unified administration will not only facilitate the coordination of healthcare insurances, but will also alleviate the financial pressure of operation. The unified policies in Foshan, Changshu and Shenyang have set successful examples for broader implementation.

Establishing a proper transferring mechanism: With the market economic development and agricultural market reforms, many rural workers transit to cities for employment, most of whom receive little NRCMS reimbursement [9]. A transferring mechanism that links with the original system could well improve the situation. But it requires a cohesive mechanism among different systems, and solving problems like how to convert payment age limitations and how to compensate for the medical funding of the local area.

Improving the coordination level: Currently, the healthcare insurance coordination remains at various levels, including county level, municipal level, and provincial level. This leads to the poor risk-resisting ability. While by improving the planning on a higher level, we could have a stronger ability to resist risks, thus increasing enrollees' confidence in healthcare insurances.

Setting up a stable fund-raising and financial subsidy mechanism: In spite of the increasing funding level, the financing mechanism is not well regulated. We propose that the payment standard of rural residents shall be set in accordance with their net income, while that of urban residents shall be set in accordance with their disposable income, and financial subsidies from the government shall be determined partially by residents' hospitalization cost.

\section{Limitations}

The study has several limitations. Firstly, the selection of the respondents focused on certain communities in the four cities, and the results may not be generalizable to the entire country due to differences among areas, and could not fully represent the three groups of population, namely, rural residents, urban residents and urban employees. Secondly, the differences of the same insurance scheme across cities were not considered when we studied the factors influencing participants' willingness towards healthcare insurance integration. Thirdly, some data in out study, like household annual income per capita, were collected on the basis of personal recall and could be prone to measurement errors.

\section{Conclusion}

This study featured enrollees' willingness towards integration of various healthcare insurances and the relevant factors. In spite of the expanding coverage of healthcare insurance, the imbalance in fairness, accessibility and affordability of the medical services have hindered the universal healthcare progress. Fear of impaired healthcare 
benefit and the differences of URBMI, NRCMS, UEBMI in aspects like administration, payment standard, benefit package, etc. were found to be the main reasons for opposing healthcare insurance integration. Therefore, the key to coordinating urban and rural healthcare insurance lies in equal financing and equal benefit. Further studies shall be conducted on the role of healthcare providers in terms of the integrated healthcare scheme. Policy makers shall find a balance between health providers and participants: enough compensation shall be distributed to health providers, mostly to public healthcare institutions, and also affordability to healthcare service shall be ensured [20] Combining the suggestions above, despite the challenges ahead, a new integrated healthcare scheme is promising and could be applied in the near future.

\section{Competing interests}

The authors declare that they have no competing interests.

\section{Authors' contributions}

XW and AZ participated in conduct of the study, data analysis and manuscript drafting. XW participated in the project design, co-ordination and conduct of the study. XH and XW participated in the project design, conduct of the study, and revision of drafts of the manuscript. All authors read and approved the final manuscript.

\section{Authors' information}

Xin Wang, female, Department of the Health Service Management, China Medical University, Associate Professor of Health Economics, PhD. Executive Director of China Health Economic Association. Director of China Soft Science Association, Master Tutor, Major Research on: Health Economic and Policy. Ang Zheng, male, Master, 97 K Seven-years system, China Medical University. Xin He, female, Master, 95 K Seven-years system, China Medical University. Hanghang Jiang, female, Master, 94 K Seven-years system, China Medical University.

\section{Acknowledgments}

This study was funded by Science and Technology Program of Liaoning Province. No.201225101: The study of fairness in medical resource distribution.

\section{Author details}

'Department of the Health Service Management, China Medical University, No.92 North Second Road, Heping District, Shenyang, Liaoning Province 110001, China(PRC). ${ }^{2}$ China Medical University seven-year system $97 \mathrm{~K}$, China Medical University, No.92 North Second Road, Heping District, Shenyang, Liaoning Province 110001, China(PRC). ${ }^{3}$ China Medical University seven-year system 95 K, China Medical University, No.92 North Second Road, Heping District, Shenyang, Liaoning Province 110001, China(PRC). ${ }^{4}$ China Medical University seven-year system 94 K, China Medical University, No.92 North Second Road, Heping District, Shenyang, Liaoning Province 110001, China(PRC).

Received: 31 October 2012 Accepted: 25 March 2014 Published: 29 March 2014

\section{References}

1. Lu M, Zhang J, Ma J, Li B, Quan H: Child health insurance coverage: a survey among temporary and permanent residents in Shanghai. BMC Health Serv Res 2008, 8:238.

2. The National People's Congress, China: Universal Coverage in an Era of Privatisation: can we guarantee health for all? [http://www.npc.gov.cn/npc/ xinwen/2010-12/25/content_1612569.htm], 2 August 2011, date last accessed.

3. Ministry of Labour and Social Security and Bureau of National Statistics: Statistical Announcement on Labour and Social Security Issues in 2006 2007 [http://www.molss.gov.cn/gb/news/2007-05/18/content_178167.htm].

4. You X, Kobayashi Y: The new cooperative medical scheme in China. Health Pol 2009, 91(1):1-9.
5. Wagstaff $A$, Lindelow $M$, Jun $G$, Ling $X$, Juncheng $Q$ : Extending health insurance to the rural population: an impact evaluation of China's new cooperative medical scheme. J Health Econ 2009, 28(1):1-19.

6. Ministry of Health: China Health Statistics Year Book. Beijing; 2012.

7. Meng Q, Xu L, Zhang Y, Qian J, Cai M, Xin Y, Gao J, Xu K, Boerma JT, Barber SL: Trends in access to health services and financial protection in China between 2003 and 2011: a cross-sectional study. Lancet 2012, 379(9818):805-814.

8. Long $\mathrm{Q}, \mathrm{Xu} \mathrm{L}$, Bekedam $\mathrm{H}$, Tang S: Changes in health expenditures in China in 2000s: has the health system reform improved affordability. Int J Equity Health 2013, 12:40.

9. Wang HQ, Liu ZH, Zhang YZ, Luo ZJ: Integration of current identity-based district-varied health insurance schemes in China: implications and challenges. Front Med 2012, 6(1):79-84.

10. Cheng ZG: Chinese social security reform and development strategyconcept, target and action plan. People's press. in press.

11. Qiu P, Yang Y, Zhang J, Ma X: Rural-to-urban migration and its implication for new cooperative medical scheme coverage and utilization in China. BMC Public Health 2011, 11:520.

12. Dong $X$, Bowles $P$ : Segmentation and discrimination in China's emerging industrial labor market. China Econ Rev 2002, 13(2-3):170-196.

13. The Central People's Government, China. [http://www.gov.cn/jrzg/200904/06/content_1278721.htm] 2 August 2011, date last accessed.

14. Gao M: Reflection on sustainability of New cooperative medical scheme from demand. Health Econ Res 2004, 10:3e6.

15. Ministry of Health: China Health Statistics Year Book. Beijing; 2009.

16. Ministry of Health: Guideline on Consolidating New Rural Cooperative Medical System. Beijing; 2009.

17. Centre for health statistics and information, M., China: An Analysis Report of National Health Services Survey in China. China, Beijing: The Ministry of Health; 2008.

18. Eggleston $K$, Ling $L$, Qingyue $M$, Lindelow $M$, Wagstaff $A$ : Health service delivery in China: a literature review. Health Econ 2008, 17(2):149-165.

19. Jian W, Chan KY, Reidpath DD, Xu L: China's rural-urban care gap shrank for chronic disease patients, but inequities persist. Health Aff (Millwood) 2010, 29(12):2189-2196.

20. Yip W, Hsiao WC, Market Watch: The Chinese health systerm at a crossroads. J Health Affairs 2008, 27:460-468.

doi:10.1186/1472-6963-14-142

Cite this article as: Wang et al: Integration of rural and urban healthcare insurance schemes in China: an empirical research. BMC Health Services Research 2014 14:142.

\section{Submit your next manuscript to BioMed Central and take full advantage of:}

- Convenient online submission

- Thorough peer review

- No space constraints or color figure charges

- Immediate publication on acceptance

- Inclusion in PubMed, CAS, Scopus and Google Scholar

- Research which is freely available for redistribution 